\title{
IDENTIDADE, ARTE E INSTITUIÇÕES: AS DISPUTAS NOS SALÕES DE ARTE NOS ANOS 1960
}

\author{
Emerson Dionisio Gomes de Oliveira*
}

\begin{abstract}
Resumo: O presente artigo procurou esboçar o comportamento dos mais importantes salões de artes visuais em quatro cidades (Belo Horizonte, Brasília, Campinas e Curitiba), nos anos 60. Realizados fora do eixo Rio-São Paulo, tais salões foram palco de disputas ligadas às questões identitárias - artistas locais e os de fora - sendo, também, arenas decisivas para diferentes vocabulários estéticos, em contextos históricos distintos. Contextos estes marcados, no campo sociopolítico, pelo período militar pós-64, e, no campo artístico, pelas discussões sobre as novas figurações, as heranças modernistas, a ampliação dos suportes e dos gêneros e a gerência da arte por mercados e crítica incipientes e museus recém-criados.
\end{abstract}

Palavras-chave: Salões de Arte. Memória. Identidade.

\begin{abstract}
This article sought to outline the behavior of the most important visual art galleries in four cites (Belo Horizonte, Brasília, Campinas and Curitiba), in the sixties. Conceived outside the Rio-São Paulo circuit, these galleries were the stage for disputes relating to identity issues - local artists and those from other parts - and were also decisive arenas for different esthetic vocabularies, in distinct historic contexts. These contexts were marked in the social political field by the post 64 military period and in the artistic field, by the discussions about the new figurations, the modernist heritages, the augmentation of supports and genres and the management of art by markets and incipient criticism and recently created museums.
\end{abstract}

Keywords: Art Galleries. Memory. Identity.

\footnotetext{
* Professor no Departamento de Artes Visuais da Universidade de Brasília.

E-mail: emerson_dionisio@hotmail.com
} 
Os anos 60 foram marcados por transformações que alteraram a relação entre a produção artística e as instituições de arte, dentro e fora dos centros culturais hegemônicos. Alterações que podem ser sentidas ainda hoje. ${ }^{1}$ Embora se possam constatar essas mudanças, algumas instituições permaneceram mais ou menos relevantes na nova configuração institucional da arte. O mais notável exemplo é o "salão de arte", que sobreviveu aos questionamentos e aos ataques empreendidos por artistas e por críticos.

Entre as diversas proposições e os diversos formatos sob o nome de "salão", o presente artigo procura mapear o contexto histórico de diferentes salões de arte fora do eixo Rio-São Paulo. ${ }^{2}$ Contexto marcado, no campo sociopolítico, pela ditadura militar a partir de 1964 e, no campo das artes visuais, pelas discussões sobre as novas figurações, as heranças concretistas e a ampliação dos suportes e dos gêneros. ${ }^{3}$ Para isso, optei por abordar quatro exemplos de instituições-evento competitivas e promotoras da visibilidade da arte do período, em Belo Horizonte, Brasília, Campinas e Curitiba. Todas elas ligadas a museus públicos ou outras instituições de memória. ${ }^{4}$ São exemplos pontuais que se apresentam dentro de um quadro heterogêneo de circunstâncias históricas, avesso a simplificações, mas que parece indicar alguns pontos comuns. Entre eles, a proposição de questões sobre a identidade da arte local e sua censura, como veremos no caso de Brasília.

A história dos salões remonta ao século XVII e está ligada à organização do fazer artístico na Europa. Academias de diferentes ordens (oficiais e dissidentes) estiveram no comando de salões importantes no Velho Continente. No caso do Brasil, deu-se o mesmo com o Salão da Imperial Academia de Bellas Artes, criado oficialmente em 1834. Após inúmeras alterações, ao gosto da política e da transição do regime monárquico para o republicano, mais de um século depois, em 1940, foi o Museu Nacional de Belas Artes que passou a organizar aquele centenário evento (chamado de Salão Nacional de Belas Artes a partir de 1931). ${ }^{5}$ Essa trajetória guarda semelhanças com a história dos salões que chegaram aos anos 60. Os "personagens" que ocuparam a cena são similares: gerência do Estado, sistema competitivo, seleção e premiação pelo "mérito", assimilação das obras pelo poder público ou instituições autorizadas, relacionamento com sistemas educacionais (escolas) ou divulgadores (museu, galerias etc.), interferência direta em mercados incipientes de arte etc. "Personagens" e fatores que se mesclam de modo diverso nos exemplos que passamos a abordar. 


\section{SALÃO PARANAENSE: ABSTRAÇÃO E IDENTIDADE}

O Salão de Arte Paranaense (SAP), iniciado em 1944, é considerado desde então o mais importante evento do gênero no Paraná. O evento é tributário dos movimentos modernizadores que se alastraram pelo Brasil uma década depois de tomarem São Paulo (Semana de Arte Moderna de 22) e o Rio de Janeiro (O Salão de 31). O grupo que introduziu a necessidade do salão na cena paranaense era formado por artistas e intelectuais, dos quais se destacaram Theodoro De Bona, Edgar Sampaio e Raul Rodrigues Gomes. O salão nasceu como Salão Paranaense de Belas Artes (SPBA), nome que indicava como fonte de inspiração o tradicional salão nacional, conduzido pela Escola Nacional de Belas Artes (ENBA).

$\mathrm{O}$ movimento que engendrou o salão estava atrelado à criação da Sociedade de Artistas do Paraná, em 1931, por iniciativa de Lange de Morretes. A sociedade, representada por pintores, escultores, músicos e arquitetos, era responsável por "defender os interesses dos cultores de arte, divulgar seus assuntos e movimentar o ambiente com conferências, concertos, exposições." Da mesma forma, foi esse grupo que, juntamente com os amigos e discípulos do pintor Alfredo Andersen (1860-1935), transportou diferentes mostras e salões dispersos, dos anos 30 e início dos 40, para os braços do Estado, criando o salão oficial.

O primeiro SPBA, como todos os remanescentes da tradição da ENBA, trouxe como protagonista a pintura. Em sua primeira edição, como nas dezessete posteriores, o salão foi organizado em duas seções: Pintura e Sala Livre (para as demais modalidades artísticas). O detalhe que coroou a pintura como técnica privilegiada sobre as outras decorreu do fato de que apenas aos pintores poderiam ser concedidas as medalhas de ouro do salão. Da mesma forma, nos poucos anos em que vigorou o mais importante prêmio concedido na história do salão, o Prêmio "Viagem Estado Brasileiro", entre 1952 e 1955, apenas pintores foram contemplados. ${ }^{7}$ Entretanto, um pouco antes do salão mudar de nome, em 1968, as demais técnicas superaram a pintura no ranking das premiações, passando por um processo de diversificação técnica que chega até os nossos dias.

A escolha do modelo acadêmico para o salão contrariava as questões abertas pelo Salão de 1931 (ou Salão dos Revolucionários ou Salão dos Tenentes) da ENBA, momento e lugar em que se acirraram os embates entre modernistas, representados pelo jovem diretor da instituição, o arquiteto Lúcio Costa, e por acadêmicos, dos quais o nome mais forte era o de Archimedes Memória. ${ }^{8}$ Os vinte anos que se seguiram ao Salão de 31 foram cruciais para a constituição de instituições abertas à arte moderna e para a alteração das diretrizes dos salões da ENBA (com a criação da Divisão dos Modernos, 
em 1940). ${ }^{9}$ Todo esse movimento, no entanto, não atingiu imediatamente os herdeiros do academicismo de Andersen. E há motivos locais para isso.

Ao contrário dos dois centros hegemônicos da cultura nacional, o Paraná estava, ainda, em plena década de 40, na busca de elementos simbólicos e históricos que definissem a identidade paranaense. O paranismo, movimento ideológico de forte eco em toda a primeira metade do século XX, possuía adeptos ainda naqueles anos. Em 1927, era fundado o Centro Paranista, que acusava o desprestígio que o estado ocupava na cena econômica, política e cultural do país. O objetivo do Centro era destacar a história e a cultura do povo paranaense. Tal movimento era a expressão do desejo regional de constituir uma identidade local destacado do resto do país. ${ }^{10}$

O movimento influenciou os primeiros salões, na medida em que todos os membros do júri eram do estado e todas as premiações até 1948 eram igualmente distribuídas entre os artistas vinculados à produção local, embora tenha havido inscritos e selecionados de fora. Os Paranaistas, todavia, sofreram, nos anos seguintes ao final de II Guerra Mundial, a oposição da geração responsável pela revista cultural "Joaquim", cujo principal nome foi Dalton Trevisan (jurado do III SPBA, em 1946). ${ }^{11}$

A "geração Joaquim" procurou combater o provincianismo do salão recém-fundado. Os principais artistas plásticos dessa geração eram o italiano eram o italiano Guido Viaro e o curitibano Poty Lazzarotto. Eles lutavam naqueles primeiros anos para que o salão adquirisse uma amplitude maior, argumentando que "Não se pode falar que a característica de nacional tenha ocorrido desde o início. Ao contrário, o Salão funcionou muito mais para os limites de Curitiba, só mais tarde se expandindo para o resto do Estado e ganhando também o Brasil.." 12

Entretanto, o salão precisou esperar muito mais que uma década após sua abertura para transformar-se numa referência nacional. A participação do artista e professor italiano José Perissionto, representando São Paulo, e do artista Martinho de Haro, de Santa Catarina, no júri do V SPBA, em 1948, da mesma forma que a premiação de Paulo Santiago, pelo Pará, e de Alfredo Oliani, por São Paulo, no salão seguinte, podem ser consideradas tímidas exceções. As premiações de 1949 eram, de fato, as primeiras concedidas a artistas não locais. Apenas no XIX SPBA, em 1962, o número de artistas premiados de fora do ambiente paranaense superou o dos premiados locais.

Antes, em 1957, insatisfeitos com as premiações "acadêmicas" do SBAP, um grupo de artistas retirou suas obras do salão e as expôs numa sala ao lado, ainda na Biblioteca Pública do Estado do Paraná, numa manifestação celebrada como o Salão dos Pré-Julgados. Dessa manifestação surgiram dois frutos importantes: o Salão Para Novos (1957) e o Círculo de Artes Plásticas do Paraná (1958). ${ }^{13}$ Este último era uma manifestação organizada de jovens artistas 
- "Movimento de Renovação das Artes Paranaenses" - que predominaria nas décadas seguintes nas principais manifestações artísticas do estado, entre elas a criação do primeiro Museu de Arte do Paraná, em 1960, e do Museu de Arte Contemporânea (MACPR), em 1970. O Salão para Novos, por sua vez, era a resposta do Poder Público para disciplinar os talentos jovens, distanciando-os dos prêmios do SBAP, o que não deu certo, pois os "novos" continuaram a ambicionar o velho salão.

O salão alterou suas feições. Em 1968, o evento passou a chamar-se apenas Salão Paranaense (SAP), despedindo-se do já combalido "Belas Artes" e posicionando-se diante do salão concorrente da época: Salão de Arte Moderna do Paraná (1960-1969). O mesmo ambiente que suscitou a mudança do nome engenharia, dois anos depois, a criação do MACPR pelo estado. $\mathrm{O}$ embate iniciado em 1957 culminou com a criação do museu, aspiração de uma geração de artistas preocupados com a substituição do legado acadêmico identitário por uma arte moderna - geralmente abstrata - com pretensões universalistas. Um integrante desse grupo foi o pintor Fernando Velloso. Ele foi o primeiro diretor do MACPR e um dos principais articuladores de sua criação em 1970. Velloso é dono de uma biografia ligada às principais instituições de artes plásticas do estado. $\mathrm{O}$ artista paranaense formou-se em artes na primeira turma da Escola de Artes do Paraná, em 1952, onde teve como principal mentor o pintor Guido Viaro, ícone da arte local. Participou pela primeira vez do SPBA em 1949, evento em que foi premiado cinco vezes $(1958,1961,1962,1963$ e 1964).

Velloso foi um ativo participante do "Movimento de Renovação das Artes Paranaenses" de 1957. Nesse período, sua obra estava marcada pelas "naturezas mortas construídas na tentativa de simplificar os objetos, dando uma sensação de presença física, de tatilidade, nas quais o volume e a perspectiva são apresentados mais pelos cortes dos planos que se interceptam e acentuam". ${ }^{15}$ Entre 1959 e 1961, ele frequentou o ateliê de André Lhote, em Paris, onde entrou em contato com o "cubismo acadêmico" do mestre francês. A passagem pela França é narrada como crucial. Ao retornar a Curitiba, engajou-se no movimento de defesa do abstracionismo. Toda uma geração que, lentamente, tomaria conta das instituições artísticas do estado:

O que se convencionou chamar de movimento abstracionista no Paraná, ou mais precisamente em Curitiba, não era nada mais, nada menos, que a culminância de um movimento que se iniciara com o objetivo de impedir o domínio que a pintura acadêmica tinha sobre todas as fontes de informações, as poucas galerias e principalmente o Departamento de Cultura, que organizava o Salão Paranaense. ${ }^{16}$ 
Dentro do movimento, o artista passou a desenvolver um estilo que foi sua marca desde então: uma pintura abstrata com elementos pós-cubistas, tipificada pela mistura entre o expressionismo lírico e versões mais construtivas nos anos 80. As telas do início dos anos 60 guardam nomes alusivos a paisagens, mas foram realizadas dentro da perspectiva abstrata, sem conter um tema figurativo explícito, como podemos ver em Composição em castanho (Figura1). "Seu abstracionismo não é nem um pouco 'hermético"." ${ }^{17}$

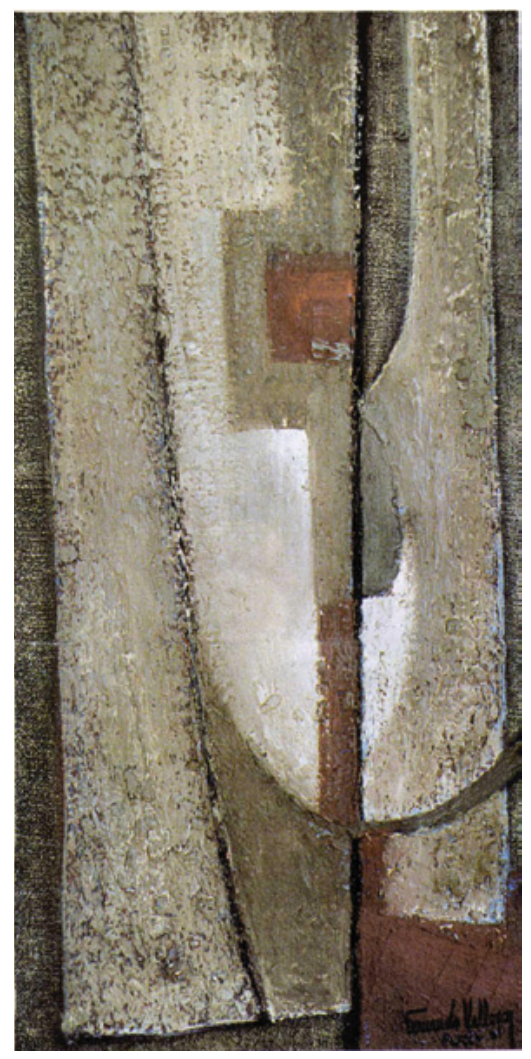

Figura 1 - Fernando Velloso, Composição em castanho, 1961, óleo sobre tela; coleção UFPR: obra premiada com a medalha de ouro no $18^{\circ}$ SPBA em 1961.

Velloso é apenas um dos exemplos do embate que a cena local importou da nacional, operada a partir do SPBA/SAP: a questão entre a arte figurativa e a abstrata:

A não-figuração, que já é predominante no Salão de 1961, consagra-se em definitivo nos Salões seguintes, em 1962 e 
1963 (...) O avanço abstrato era tão evidente no Estado que já em 1961 Garfunkel, usando uma expressão de Botteri, acusa o júri do Salão Paranaense de favorecimento aos 'imperativos da ditadura abstracionista'. ${ }^{18}$

Outros artistas abstratos foram premiados nos salões ao longo dos anos $60^{19}$, o que, em tese, atrasou a entrada e a premiação de um conjunto de obras ligadas ao realismo político e ao universo pop que despontavam nas cenas paulista e fluminense. Todavia, as mudanças mais importantes foram a abertura para a arte "exterior" e a proximidade de uma linguagem mais contemporânea.

\section{SALÃO DE ARTE CONTEMPORÂNEA DE CAMPINAS: POR UMA OUTRA VANGUARDA}

Ao contrário do que aconteceu na capital paranaense, em Campinas a necessidade era criar um salão que já estivesse livre das premissas acadêmicas e que pudesse comungar com o ambiente artístico dos anos 60. A história do Salão de Arte Contemporânea de Campinas (SACC) está atrelada à do Museu de Arte Contemporânea (MACC) da cidade. O SACC e o MACC nasceram juntos. O Salão foi o álibi para a constituição de uma Pinacoteca Municipal no início de $1965 .{ }^{20}$ A sua primeira versão ocorreu no final do mês de agosto do mesmo ano e, no mês seguinte, o sonho da Pinacoteca (nome combatido pelos "vanguardistas" da cidade ${ }^{21}$ ) tinha se transformado num museu de arte contemporânea, bem ao gosto do museu que havia nascido na capital do Estado pelas mãos da Universidade de São Paulo, em 1963. ${ }^{22}$

A história dos SACCs começou na década anterior, com a $1 .{ }^{a}$ Exposição de Arte Contemporânea de Campinas. Realizada em setembro de 1957, ela reuniu jovens artistas dedicados a atualizar a arte da cidade, diante do impacto das três primeiras Bienais de São Paulo. O local escolhido foi o hall do Teatro Municipal, até então palco privilegiado das exposições campineiras, onde, geralmente, era divulgada a arte dos "mestres" acadêmicos locais. ${ }^{23}$

Menos que perturbar a tradição, o movimento que se instituiu a partir dessa exposição e que, no ano seguinte, ficou conhecido como Vanguarda, estava inicialmente interessado em conquistar espaço, agenda e mercado para um grupo jovem, que indubitavelmente já havia iniciado o movimento de descolamento da cena acadêmica. Como bem informou o crítico e jornalista José de Castro Mendes num texto do período, a mostra agrupava trabalhos que traziam "uma mensagem renovadora". 24

As investidas contra a exposição acabaram por suscitar, no ano seguinte, uma resposta mais organizada e consciente, com a criação do Grupo Vanguarda, celebrada com a 2. ${ }^{a}$ Exposição de Arte Contemporânea de Campinas. O evento 
ocupou o andar térreo do Edifício Catedral, no centro da cidade. Os participantes foram praticamente os mesmos. ${ }^{25}$ Ainda naquele mesmo ano, outras três exposições, sob a nomenclatura "arte contemporânea", foram organizadas, todas com o mesmo caráter e reunindo os mesmos artistas. ${ }^{26}$

O mesmo grupo foi responsável, em 1965, pela criação do SACC, ao lado de outros importantes articuladores, como a Profa. Jacy Milani, então responsável pela Secretaria Municipal de Educação e Cultura. Notícias colhidas no principal jornal de Campinas mostram-nos a importância do evento. ${ }^{27} \mathrm{O}$ SACC é acolhido como um fenômeno de grande valia para ligar a cidade aos centros culturais do país, uma "mostra de arte de vanguarda", que se esmerava em trazer as tendências mais apreciadas no momento:

Modernas manifestações da 'pop-art', da ingenuidade dos primitivistas, da agonia e desespero dos surrealistas, passando ainda pelo concretismo e abstracionismo (pictórico, geométrico ou lírico), do realismo fantástico (com sua discutida nova figuração), tachismo, gravura, xilogravura, desenho, água-forte, painéis de cerâmica e vidro. ${ }^{28}$

O SACC foi um produto representado como uma ruptura com as formas de salões anteriores da cidade, especialmente em relação ao Salão de Belas Artes de Campinas. Longe de narrá-lo como continuidade, os artistas que o criaram viam-no como elemento de uma evolução natural da arte e, portanto, como evento superior aos anteriores, por sua atualidade ${ }^{29}$, mesmo procedendo como um típico salão da primeira metade do século XX, tão convencional quanto o sistema de premiação representado por distribuição de medalhas dos primeiros SACCs. ${ }^{30}$ Por outro lado, procuraram ao máximo vinculá-lo ao ambiente das artes plásticas de São Paulo, convidando, para compor os primeiros corpos jurados, figuras de grande influência na cena artística da capital, tais como: Mário Schenberg, Walter Zanini, José Geraldo Vieira e Aracy Amaral. A típica recorrência dos nomes entre os jurados dá-nos a noção do quão comprometidos estavam os primeiros momentos do salão e do museu com as circulações artísticas paulistanas. $\mathrm{O}$ que de fato pode ajudar a explicar a facilidade da mudança do nome Pinacoteca para o vitorioso "Arte Contemporânea" - nome derivado do salão.

As sete versões posteriores à primeira mostraram-se regulares, alterando as configurações dos prêmios e os dados do regulamento e mantendo a premissa de que a base essencial do evento era mostrar à cidade o que de "novo" havia na arte. Ao mesmo tempo, o Salão apresentava a arte produzida em Campinas a um corpo jurado oriundo predominantemente de São Paulo. A pesquisadora 
Renata Zago lembra-nos de que, segundo o crítico e historiador da arte José Roberto Teixeira Leite - membro dos júris de 1969 e de 1970 -, os salões eram considerados "laboratórios" para as Bienais de São Paulo. ${ }^{31}$ Com essa concepção, a aquisição de obras para o novo museu surgiu como função secundária do Salão.

Diferentemente do que podemos ler no SAP e em outros salões regionais - em que os eventos ora eram orientados para um localismo, ora para privilegiar o "estrangeiro" como forma de autorizar o próprio salão nos âmbitos local e nacional -, o SACC preferiu funcionar numa "falsa" ambivalência, que, de modo adverso, não contentou o meio cultural local, retirando, assim, em boa medida o alicerce político de sua constituição.

Da mesma forma, os artistas campineiros - que renderam tantos tributos a críticos e divulgadores de arte provenientes da cena paulistana com a finalidade de projetar seus trabalhos naquela cidade - obtiveram sucessos temporários (incluindo participações nas Bienais Internacionais de São Paulo), uma vez que suas carreiras não conseguiram adentrar o competitivo e restrito mercado de arte nacional. Já no I SACC, em 1965, o corpo jurado concedeu prêmios de caráter aquisitivo e estimulou predominantemente doações de artistas de fora da cidade. Prática comum nos seis anos que se seguiram.

O primeiro grupo de obras do MACC é, dessa forma, um panorama limitado, embora importante, do início da carreira de artistas que fizeram, anos depois, parte da cena nacional das artes visuais. Se é verdade que o corpo jurado traz consigo os artistas sob sua influência direta para concorrer num salão, os premiados e mencionados (menção honrosa) locais não tiveram bons "advogados" nas primeiras cinco edições do SACC. Se tomarmos apenas o salão inaugural e os registros do museu, predominaram artistas vindos de São Paulo e de outras regiões do país (esses em menor número), em detrimento aos "vanguardistas" locais.

O relato de Raul Porto, artista "vanguardista", sobre esse momento, colhido por Crispim Campos nos anos 90, dá-nos pistas sobre o embate:

Nós tivemos uma coisa boa, que foi a criação do MACC, mas em seguida, tivemos uma infiltração 'perigosa', pelo grupo Frei Caneca, e houve uma neutralização dos artistas de Campinas. Tivemos uma pessoa que salvaguardava os interesses desse grupo, que é a Lourdes Cedran. Lourdes conseguiu, em certa época, bloquear os artistas de Campinas, para dar passagem para os artistas de São Paulo. Ela tinha força, porque ela foi diretora do MACC. (...) Ela conseguia fazer as vias de acesso, para esses artistas de São Paulo, eles queriam se projetar e a forma de se projetar era através do salão. ${ }^{32}$ 
Não que os artistas locais não tivessem se articulado para influir mais diretamente no salão, mas aqueles últimos anos da década de 60 mostraramse pouco propícios a conciliações; estavam marcados pelo signo das posições ideológicas vigiadas pelo Estado policial vigente. A tensão entre a produção local e o assédio dos grandes polos difusores de arte (São Paulo e Rio de Janeiro) permaneceu nos anos seguintes, com pequenas variações nos embates. O ápice da distância entre a representação da produção local e as necessidades curatoriais externas foi o X SACC, para o qual foram convidados doze artistas, a fim de debaterem suas obras com críticos e com o público. Apenas Mário Bueno representava a arte campineira. ${ }^{33}$

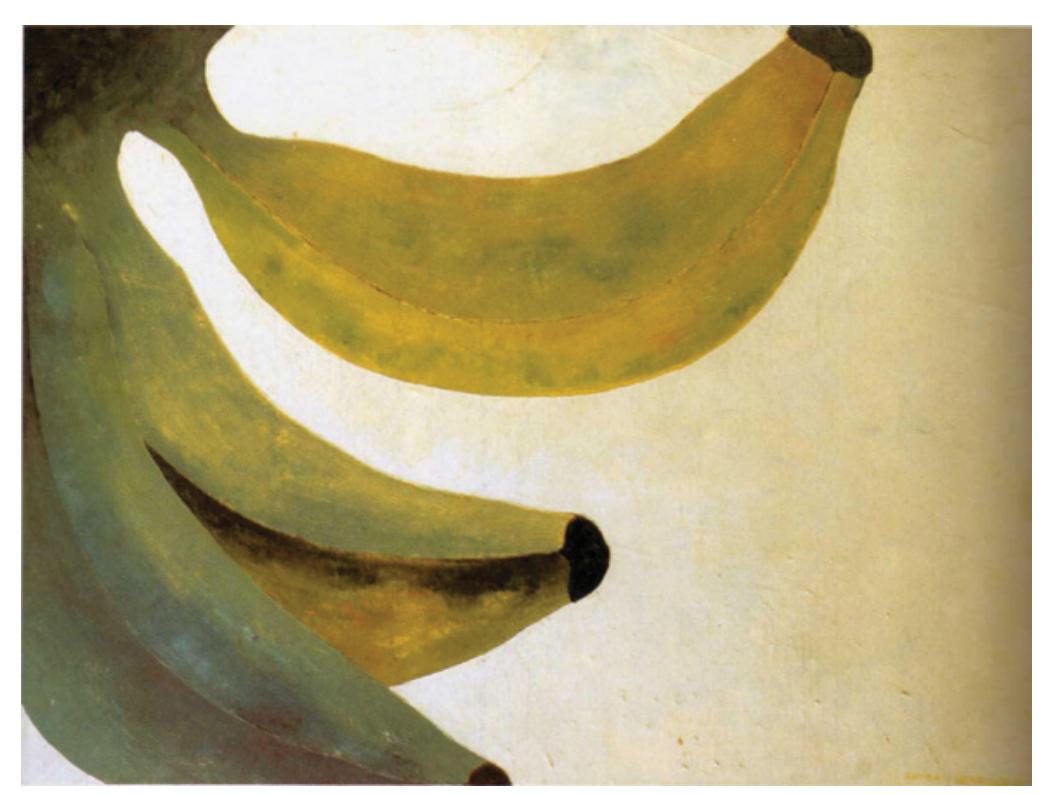

Figura 2 - Antonio Henrique Amaral, Brasiliana 1, 1968, óleo sobre tela, coleção do MACC.

O legado dos SACCs apresenta, dessa forma, duas dimensões. A primeira diz respeito à aproximação com a cena artística nacional, trazendo para Campinas obras de artistas de uma reconhecida heterogeneidade, tais como: Mira Schendel, Carmela Gross, Antonio Henrique Amaral (Figura 2), José Roberto Aguilar, Evandro Carlos Jardim, Lolthar Charoux, Marcelo Nitsche, Cláudio Tozzi, Antonio Manuel, Anna Maria Maiolino, Emanuel Araújo, Humberto Espíndola, Tomoshige Kusuno, apenas para citar premiados dos anos 60. A outra se refere ao fim da articulação do grupo que criou o SACC e a seu lento e gradativo distanciamento das decisões e premiações concernentes ao salão. 


\section{SALÃO MUNICIPAL DE BELAS ARTES DE BELO HORIZONTE: EXPERIMENTAÇÕES, RUPTURA E CONFLITOS}

Os SACCs não foram os únicos salões a ter sua história matizada pelas críticas aos valores utilizados nas seleções. Em Belo Horizonte, o epicentro da polêmica nos anos 60 tinha um nome: XXII Salão Municipal de Belas Artes de 1967. Antes é preciso contextualizar historicamente a relevância dos salões para a cidade, numa perspectiva da história da arte local.

Coube à Administração Municipal da cidade a realização daquele que pode ser considerado o marco inicial do modernismo belo-horizontino: $\mathrm{O}$ Salão Bar Brasil. Realizado em 1936, no Bar Brasil - localizado no subsolo do antigo Cine Brasil -, e organizado por Delpino Júnior, foi marcado pela aproximação a uma linguagem visual dedicada ao vocabulário modernista. ${ }^{34} \mathrm{~A}$ transição não significou, naquele momento, uma ruptura com a linguagem mais convencional, antes configurou o ingresso de novas ideias visuais, assistido por artistas acadêmicos, cujo representante mais conhecido, o artista Aníbal Matos - até então o nome símbolo da arte "oficial" da cidade -, endossara a realização. Independentemente de qualquer disputa, o Salão Bar Brasil serviu para reivindicar a criação de um salão de arte permanente, mantido pela esfera pública e que oferecesse aos artistas locais um espaço de visibilidade, o que ocorreu em 1937, com o I Salão Municipal de Belas Artes de Belo Horizonte (SMBA).

Se o Salão do Bar Brasil abriu as portas para a arte moderna, a consolidação dessa nova linguagem veio, em 1944, com a Exposição Moderna, na gestão do prefeito Juscelino Kubitscheck. A mostra tinha à frente da organização Alberto da Veiga Guignard e José Guimarães Menegale, que conseguiram reunir expressivos nomes do cânone modernista da época - em parte graças ao envolvimento de Gustavo Capanema e Rodrigo de Melo Franco. Estavam presentes: Anita Mafalti,Volpi, Clóvis Graciano, Santa Rosa, Milton Dacosta, Mário Levi, Osvaldo Goeldi, Tarsila do Amaral, Rebolo, Lívio Abramo, Lasar Segall, Paulo Rossi Osir, Di Cavalcanti, Quirino Campofiorito, Mario Zanini, José Pancetti, Candido Portinari, o próprio Guignard, entre outros artistas e intelectuais. ${ }^{35}$ A exposição de 1944 possibilitou que toda uma geração de artistas locais se debruçasse sobre a produção da arte moderna, localmente identificada na trajetória da Escola Guignard.

Alberto da Veiga Guignard fora convidado para lecionar pintura na Escola de Belas Artes em 1943. Tratava-se do início da institucionalização da arte moderna, que conheceu, ao longo dos vinte anos posteriores, avanços e reveses importantes com a fusão de instituições e a criação de outras. ${ }^{36}$ 
Pela Escola passou toda uma geração de artistas mineiros que iniciou sua carreira dentro do vocabulário estético modernista, como Mary Vieira, Yara Tupynambá, Álvaro Apocalypse, Jefferson Lodi, Jarbas Juarez, Maria Helena Andrés, Amílcar de Castro, Farnese de Andrade, Franz Weissmann, Mário Silésio, entre outros.

Mesmo passando por crises seguidas, foi sobre a influência da Escola Guignard que o SMBA passou por uma reforma em 1960, em sua décima quinta edição. A principal alteração foi a abertura das inscrições, e consequentes premiações, para artistas não locais. Atitude em plena consonância com o convite de críticos e de artistas consagrados externos à cena mineira para compor o corpo jurado. Como nos pares analisados acima, o SMBA passava por um período de "nacionalização" de suas ambições, na busca de reconhecimento, sobretudo dos artistas e dos críticos do eixo Rio-São Paulo. Outra mudança importante, já sob a ótica patrimonial, é a criação de prêmios aquisitivos em favor do acervo Museu da Pampulha.

Os salões de arte de Belo Horizonte, patrocinados pela prefeitura da cidade, foram divididos em três fases por Rodrigo Vivas: Salão de Belas Artes (1937 - 1960), Salão Municipal de Belas Arte (1960-1968) e o Salão Nacional de Arte Contemporânea (1969). ${ }^{37}$ Interessam-me os salões posteriores a 1960, que marcam a ruptura com o legado da arte moderna (ainda com a presença e o sotaque da arte acadêmica) e o surgimento da neovanguarda local, que introduziu preceitos que mais tarde serão compreendidos como os primórdios da arte contemporânea.

Os novos SMBAs, na década de 60 , também coincidiram com o desaparecimento de Guignard, em 1962 e, de certo modo, com o início da ascensão de uma nova geração de artistas, que não mais comungava com a cartilha do velho mestre. Também foi, segundo Ribeiro, o período de profissionalização do mercado de arte na cidade e da estruturação da crítica nos meios de comunicação. ${ }^{38}$ Nos anos 60 , todo um elenco de novos personagens passou a definir qual arte teria a visibilidade no circuito, claro, não sem controvérsias.

As questões identitárias fizeram-se presentes. A controvérsia mais evidente foi o choque entre artistas locais e aqueles que vinham de fora. Já em 1960, no XV SMBA, as críticas podiam ser resumidas pela manchete do jornal Diário da Tarde do dia 03 de dezembro: "XV Salão de Belas Artes violou a lei: admitiu artistas de fora". Apesar da polêmica, a abertura aos "de fora" permaneceu, e artistas de outras partes do país passaram a influenciar diretamente a história do evento. ${ }^{39}$

No XVIII SMBA, em 1963, as críticas retornaram com a mesma reivindicação quando o júri, composto por José Geraldo Vieira, Mário Pedrosa, Clarival Valladares, João Quaglia e Rui Flores, rejeitou a maioria dos trabalhos 
inscritos. O rigor excessivo para a produção local foi o tom adotado naquele momento, uma vez que pareceu difícil discutir a capacidade do júri: "Os artistas de Minas estão mais do que descontentes com a decisão do júri que julgou os trabalhos do XVIII Salão Municipal de Belas Artes. A maioria dos trabalhos foi cortada, e há muitas fofocas na praça. Os premiados são principalmente de fora". ${ }^{40}$ Em sua maioria locais, os artistas rejeitados acabaram criando o Salão dos Recusados. A polêmica, dessa vez, gerou atritos que ultrapassaram as fronteiras mineiras e tiveram eco em jornais do Rio de Janeiro e de São Paulo, o que demonstrava o crescente interesse e a visibilidade do salão mineiro.

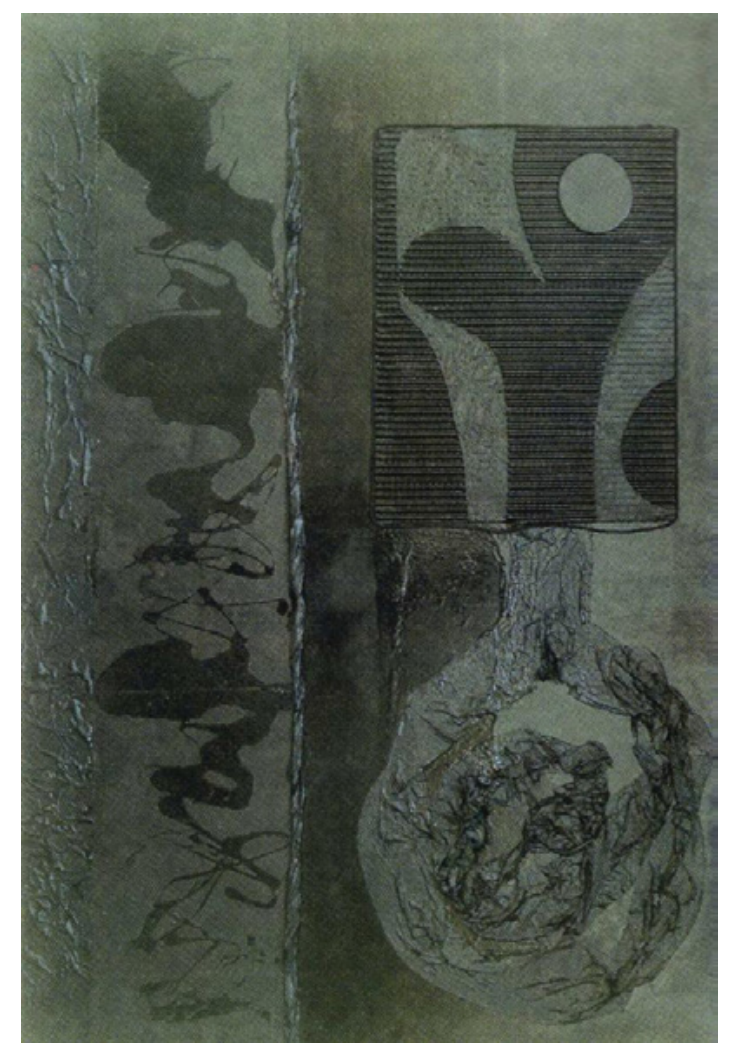

Figura 3 - Jarbas Juarez, Composição em preto, 1964, óleo, tinta automotiva e colagem sobre tela, coleção do MAP.

Diante das críticas pesadas, o salão seguinte, em 1964, modificou pouco sua direção. Ainda sob o comando de Mário Pedrosa, José Geraldo Vieira e Clarival Valladares, acompanhados de Joaquim Mendonsa e Maristella Tristão, o XIX SMBA também optou por cortar a maioria dos inscritos (na categoria escultura, apenas cinco artistas foram escolhidos dos 25 inscritos) e premiar jovens artistas ligados às novas linguagens - independentemente do seu lugar 
de origem. As polêmicas se instituíram novamente, mas, agora, com um fato novo: o histórico manifesto do então premiado artista Jarbas Juarez.

O primeiro prêmio de pintura para Juarez é considerado por Ribeiro como um marco para a neovanguarda em Belo Horizonte. ${ }^{41}$ Mais que sua obra, Composição em Preto (Figura 3), Juarez afeta a cena local, negando e contrariando a geração anterior, ainda ligada ao modelo da Escola Guignard. Juarez decretava: "Guignard está morto, descubramos nossos próprios caminhos!" 42 Para o artista, o legado de Guignard, sobretudo o modo de pintar Minas, estava irremediavelmente ultrapassado.

A questão entre os artistas locais e aqueles oriundos de fora perdura em 1965, na vigésima edição do salão. Com premiações financeiramente mais atraentes, artistas de todo o país interessam-se pelo evento enquanto notícias de uma mobilização local com a intenção de influenciar na escolha dos membros do júri pareciam antecipar um novo conflito: "Os artistas mineiros acham que têm menores chances com esse pessoal que vem de fora. E estão se organizando, cabalizando e fofocando para botar no júri dois elementos locais que briguem pela premiação de artistas mineiros." ${ }^{43}$ Os esforços não foram suficientes para impedir a premiação de Yo Yoshitome e Ivan Serpa (este último com o prêmio aquisição). Menos polêmico, o salão de 1966 premiou Tomie Ohtake e Eduardo de Paula. Naquele ano, o SMBA perdeu em atenção - ao menos no plano da memória - para a Exposição Vanguarda Brasileira, sob comando de Frederico Morais, que levava para a cidade as discussões sobre o novo realismo, debatido no ano anterior nas famosas mostras Opinião 65 e Proposta 65, respectivamente no Rio de Janeiro (MAM) e em São Paulo (FAAP). ${ }^{44}$ A exposição de Morais colocou Belo Horizonte no caminho das discussões operadas nos grandes centros culturais do país, o que afetou decisivamente a edição seguinte do SMBA.

O XXII Salão Municipal de Belas Artes de 1967 foi o ponto alto da disputa entre artistas locais e artistas de fora. O júri ${ }^{45}$ optou por premiar Eduardo Aragão, Angêlo Aquino e Maria do Carmo Secco (esta no polêmico prêmio "pesquisa"). O jornalista e crítico Wilson Frade - com a ajuda de Motta - e outros artistas colocaram-se contrários às escolhas dos jurados e entraram na justiça pedindo a anulação do salão. $\mathrm{Na}$ ocasião, Frade permanece atrelado ao discurso identitário e pouco preocupado em debater as novas linguagens artísticas preferidas pelo júri. O crítico, crente de que o salão seria anulado, escreve: "Acredito que se tal acontecer será uma vitória dos artistas mineiros que lutam e trabalham por um lugar ao sol e são sistematicamente alijados em favor de artistas componentes das chamadas 'panelas'."46

O júri estava sendo acusado de ter premiado "pseudoartistas" de vanguarda em vez de ater-se a carreiras sólidas do ambiente local. Ribeiro lembra-nos de que o termo vanguarda passava a designar um "movimento 
artístico inovador" ${ }^{47}$, enquanto Vivas interpreta o termo, nessa ocasião, como indicativo de uma "geração de artistas cariocas e paulistas que se reuniam na primeira metade da década de 1960". ${ }^{48}$

O Salão não foi anulado, mas a disputa entre os diferentes lados, simbolizados por Morgan Motta e por Frederico Morais, parecia refletir o clima político da época. A nova vanguarda fazia-se representar por meio de críticas aos costumes, à tradição da arte e à repressão da ditadura. Do outro lado, o discurso permanecia instituído na ideia de que dinheiro público de Belo Horizonte estava sendo usado para prejudicar artistas locais. Para o artista Márcio Sampaio, o salão de 1967 marcava uma nova etapa na história da arte de Minas, uma vez que instituiu, contra todas as adversidades, um debate sobre os critérios de seleção e premiação, bem como discutiu o papel da crítica e dos jurados. ${ }^{49}$

Em 1969, Sampaio esteve à frente do salão. Com dificuldades para viabilizar sua vigésima terceira edição, o Museu da Pampulha acabou por construir uma agenda que impossibilitou a participação de artistas residentes fora da cidade. A seleção realizada por Donato Ferrari, Jaime Maruício, Morgan Motta, Walmir Ayala e Sampaio acabou por escolher um número maior de trabalhos locais e premiou artistas como Eduardo de Paula, Teresinha Soares e Yutaka Toyota (prêmio pesquisa); artistas preocupados com as linguagens da incipiente arte contemporânea. De qualquer modo, o ano termina com o fim da nomenclatura SMBA. Nascia o Salão Nacional de Arte Contemporânea (SNAC).

A primeira mudança do SNAC, em 1969, foi abolir a divisão de gêneros e suportes, conferindo-lhe um diferencial importante em relação à tradição e à hierarquização das belas artes. Diferencial que abria o salão às propostas interdisciplinares da arte contemporânea que encontravam dificuldade em encaixar-se em nomenclaturas convencionais (desenho, pintura, escultura etc. $)^{50}$ O júri era composto por Jacques do Prado Brandão, Jayme Maurício, Morgan da Motta, Roberto Pontual e Sampaio, então conservador-chefe do MAP. A premiação pareceu superar as disputas entre locais e os de "fora", uma vez toda uma geração de artistas contemporâneos locais já se encontrava dentro dos trânsitos das artes visuais no Rio de Janeiro e em São Paulo. Além disso, para Ribeiro a premiação denotava um certo ecletismo apaziguador:

Contemplando linguagens convencionais e experimentais. Os desenhos geométricos de Zaluar, João Sérgio Souza Lima e Wanda Pimentel, ao lado dos desenhos figurativos de Pompéia Brito, Zama, José Avelino de Paula e das pinturas geométricas de Lothar Charoux encontravam-se na vertente convencional do Salão. Já os livros-objetos 
de Raimundo Colares versando sobre os gibis, os amplos desenhos narrativos de Sérgio de Paula (Gastrópodes), que contavam histórias de um banco de carneiros, somados às Faixas Litográficas de Lotus Lobo, às pinturas-objeto de Décio Noviello, bem como às Bovinoculturas de Humberto Espíndola, se encontravam na vertente inovadora daquele Salão. ${ }^{51}$

O SNAC não parece ter interrompido a disputa entre a produção local e aquela proveniente de outras partes do país, todavia, graças à reorganização da circulação das artes nos ano 70 e 80 , as instituições - sejam os museus, sejam os salões - passaram por críticas e questionamentos que deixaram parte dos problemas identitários em segundo plano.

\section{SALÃO DE ARTE MODERNA DE BRASÍLIA: POLÊMICA E AMBIÇÕES NACIONAIS}

A identidade da arte acaba por aproximar os salões do Paraná, de Belo Horizonte e de Campinas, o que não ocorreu com a experiência empreendida em Brasília. Criado em 1964, o Salão de Arte Moderna de Brasília (SAMB) conheceu apenas quatro edições. Ao contrário dos cenários anteriores, a recémfundada capital do país guardava uma conformação diversa, que dava ao SAMB liberdade para flertar com dinâmicas artísticas de diferentes partes do país, pois Brasília era uma criação cuja identidade movia-se entre uma multiplicidade de "híbridos" reunidos que formavam um amálgama difícil de mensurar a partir de fenômenos culturais isolados, numa "sobrecarga de identidades". ${ }^{52}$ Tal especificidade cultural, inédita na história brasileira, trouxe para as discussões "temporalidades" artísticas diferentes, provenientes de todo o país, num curto período histórico, algo que explica, em parte, a dificuldade da própria escolha de um projeto museal de arte para a capital. ${ }^{53}$

Após alguns projetos frustrados, a capital só teria um museu de arte em 1985, com inauguração do Museu de Arte de Brasília (MAB). No catálogo de abertura da instituição, o museólogo João Evangelista Andrade Filho mencionava que os salões ocuparam um importante papel na definição da coleção do MAB. O mais importante deles, para a engenharia de prestígio do museu até 1985, foi o Salão de Arte Moderna de Brasília. O SAMB foi uma instituição ambiciosa, que pretendia transformar-se num relevante evento do gênero, rivalizando com seus pares, o salão nacional e o salão paulista.

Organizados pela Fundação Cultural de Brasília, instituição criada em janeiro de 1961, a abrangência dos SAMBs mirava a arte em plena metamorfose nos grandes centros do país. As obras premiadas e adquiridas 
refletem a importância que os SMABs tiveram quase que imediatamente ao seu surgimento; nomes emergentes na cena artística nacional, como por exemplo: Frank Schaeffer (I SAMB), Marcelo Grassmann (I SAMB), Cildo Meireles (II SAMB), Tomie Ohtake (II SAMB), Maria Bonomi (III SAMB), Farnese de Andrade (III SAMB), João Câmara (IV SAMB/ fig.4), Anna Bella Geiger (IV SAMB), Marcelo Nitsche (IV SAMB) e José Resende, entre outros..$^{54}$ Do mesmo modo que os SACCs, os organizadores apoiaram-se em profissionais gestores e críticos vindos do Rio de Janeiro e de São Paulo para alçar o evento: Qurino Campofiorito (I e II SAMBs), Harry Laus (I e II SAMBs), Geraldo Ferraz (II SAMB), Walter Zanini (II e IV SAMBs), José Geraldo Vieira (III SAMB), Olívio Tavares de Araújo (III SAMB), Frederico Morais (IV SAMB) e Mário Pedrosa (IV SAMB), entre outros. Contudo, as ambições naufragaram muito rapidamente, e um episódio famoso e amplamente comentado pela história institucional da arte brasileira ajuda entender o porquê.

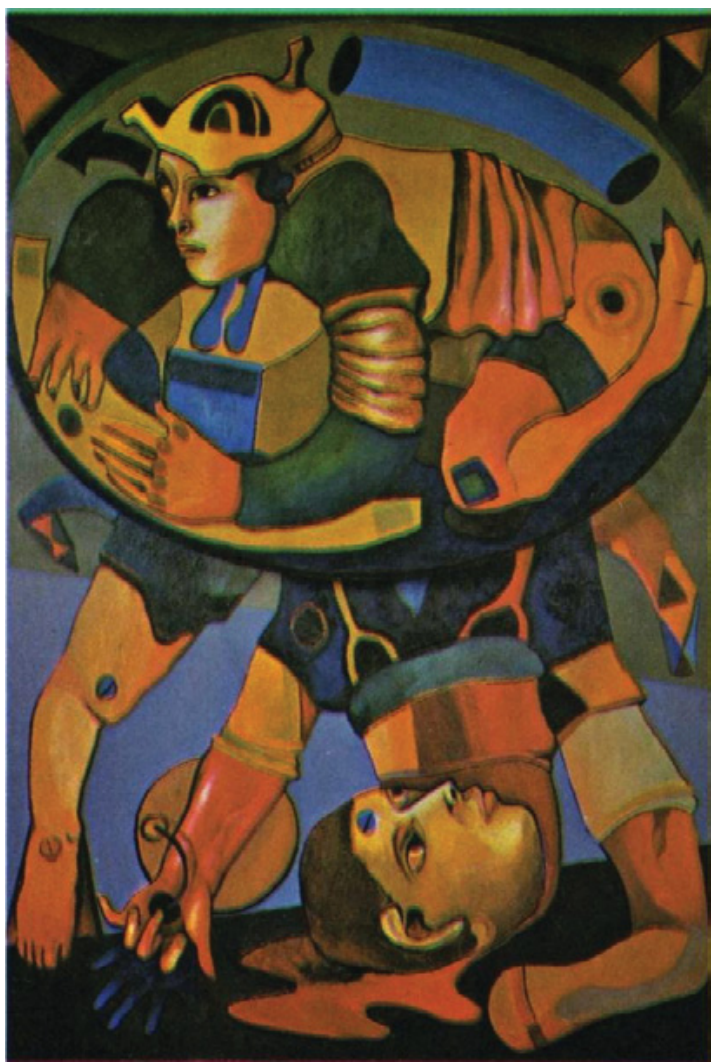

Figura 4 - João Câmara, Exposição e motivos da violência, 1967, três peças de encáustica e óleo sobre madeira em relevo (detalhe): coleção MAB. 
Desde o fim do modelo das Belas Artes, em diferentes quadrantes, salões vinham colhendo críticas sobre suas reais funções e muitos se mostraram convulsionados nos anos $60 .{ }^{55}$ O IV SAMB, em 1967, não foi diferente de tantos outros casos, mas marcou a história graças a um porco empalhado, enviado ao júri pelo então jovem artista Nelson Leirner. A inscrição de $O$ porco empalhado, como explica o artista, tinha uma finalidade provocativa e visava, de modo confesso, que ele fosse recusado pelo júri. Contudo, o corpo jurado, chefiado por Mário Pedrosa, aceitou-o, o que levou o artista a questionar, em uma nota publicada em 21 de dezembro do mesmo ano pelo Jornal da Tarde de São Paulo, os critérios adotados pelos jurados para incluí-lo. ${ }^{56} \mathrm{O}$ artista esclareceu anos depois que:

Ia ser um trabalho político. Era um porco empalhado numa grade e tinha uma corrente no pescoço e acompanhava um presunto que foi consumido no caminho; comeram o presunto e deixaram só a corrente. Essa era a obra. Mas havia um conceito por trás do trabalho. Era a relação entre o produto industrializado, que era o presunto, e a forma bruta, que era o porco. E a idéia era o porco ir a Brasília. Aceito ou não, ele voltaria, e quando ele voltasse - eu já tinha combinado com um amigo meu - eu iria condecorar o porco por sua ida. Agora, como o porco foi aceito, me bateu aquela luz de falar com o Ivan Angelo, e ele publicou na página 2 do Jornal da Tarde a foto do porco e a frase: "O artista Nelson Leirner quer saber por que o porco foi aceito como obra de arte". Aí causou toda uma polêmica, porque parte do júri começou a justificar por que tinha aceito, outra parte disse que não tinha compartilhado da decisão. As pessoas começaram a escrever coisas sobre o júri, dizendo que eles não entendiam de arte. E foram três meses de artigos sobre o júri, e eu e o meu trabalho desaparecemos de cena. ${ }^{57}$

Atrevo-me a dizer que, pelo modo como o fato é recorrentemente narrado pela história da arte brasileira, a polêmica foi suficientemente conhecida para colocar na defensiva uma considerável parte do sistema de salões, momento em que muitos desses eventos foram extintos ou passaram por crises debatidas com timidez em pleno regime militar. Contudo, a instituição-salão sabia escolher seus argumentos, colhidos nas narrativas oficiais da história da arte, para refutar os ataques, como demonstra exemplarmente a resposta de Pedrosa:

Esperava Nelson Leirner que o júri a tivesse recusado? Por que não tinha valor plástico? Por que não era 'uma obra de arte'? Por que não fora 'criada' ou não tinha originalidade? 
Mas se se trata de um 'porco empalhado', alguém o empalhou. Empalhar animais é uma arte reconhecida e apreciada, a taxidermia. É também Nelson perito nela? Mas se ele apenas comprou o porco empalhado engradado e mandou a Brasília, a obra cai na categoria dos ready-made à la Duchamp. Queria o jovem artista que o Júri fosse negar validez (ainda reconhecendo seus precedentes) a essa proposição, uma das mais ricas de conseqüências, que se bolaram desde Dada, no mesmo contexto de desmistificação cultural e estética? [...] Na arte pós-moderna, a idéia, a atitude por trás do artista é decisiva. ${ }^{58}$

A capacidade de absorver as críticas é um hábito de instituições que primam pela sobrevivência e por representarem-se como perenes. Todavia, a resposta de Pedrosa, invocando aquele que seria o "pai" da arte contemporânea, não poupou o SAMB do descrédito e da extinção. ${ }^{59} \mathrm{Um}$ aspecto que não pode ser ignorado vem do fato de que o IV SAMB foi um dos primeiros a sofrer uma forte pressão da censura (os trabalhos de José Roberto Aguilar e Cláudio Tozzi foram retirados por serem considerados políticos) - ao lado II Bienal Nacional de Salvador, fechada pela repressão em 1967, e da intervenção no III Salão de Ouro Preto em 1969, casos mais famosos. Segundo Frederico Morais, membro do júri, os jurados conseguiram convencer, a duras penas, os censores a não retirar obras da mostra. ${ }^{60}$

$\mathrm{Na}$ curta história dos SAMBs, as críticas realizadas em Brasília foram, em geral, conservadoras:

É um tal de artista colecionar tampinhas de cerveja, plásticos coloridos, objetos inusitados como máscaras contra gases (vide III salão) e outros sem valor como molas velhas, rolhas, etc. Tudo isto muito bem disposto em tela para se ter a impressão de que se trata de Pintura. E nós que apreciamos arte moderna, chegamos a dar razão àquele refrão popular do 'assim até eu faço'. Mas o III Salão trouxe uma vantagem: se $99 \%$ não entendiam de arte, podemos ter certeza de que, agora, já $100 \%$ não a entendem. ${ }^{61}$

A pesada crítica de Laet mostra-nos que, embora tenha havido um esforço de alguns segmentos das artes visuais na cidade para transformar o SAMB numa referência nacional, alinhado às prerrogativas das neovanguardas que surgiam em outras capitais do país, Brasília não apresentou, como Rio de Janeiro, São Paulo e, mesmo, Belo Horizonte, alternativas que permitissem o debate sobre a produção mais experimental. Além disso, como lembra 
Aline Figueiredo, havia o problema da administração precária dos salões: “A Fundação funcionava num pequeno barracão, improvisado no Eixo Monumental. E a carência de instalações apropriadas e alguns problemas com censura, levaram-na a interromper esses salões. ${ }^{62}$

\section{COMPETIÇÕES, ARTE E IDENTIDADE(S)}

O fato de este artigo ter escolhido dois salões que permanecem atuantes (SAP e SNAC) e dois salões que não conseguiram perpetuar-se (SAMBs e SACCs) é sintomático de que não há muitas regras para avaliar estas instituições-evento, que adquiriram feições diferentes mesmo tendo, em sua estrutura, "personagens" conhecidos. Os salões foram personagens importantes na representação das memórias e da história das artes visuais das comunidades indicadas. ${ }^{63}$ Do protocolar SPBA ao eclético SNAC, o evento-instituição levou para arena pública questões identitárias, lógicas de mercado, rivalidades entre artistas locais e "estrangeiros", a censura e o descaso ${ }^{64}$, além de toda uma gama de obras de arte absorvidas por diferentes instituições públicas, como os museus locais. Juntos e separados pela finalidade, os quatro salões analisados indicaram disputas e competições distintas.

Nos casos de Curitiba, de Belo Horizonte e de Campinas, o que parece estar em jogo são as relações identitárias que procuraram definir uma arte local - geralmente atrelada ao frágil argumento da "arte natal" - em relação à produção oriunda de "fora". A questão, entretanto, é não cair no discurso fácil de compreender o local como conservador, como indica a atuação dos artistas paranaenses e mineiros no final dos anos 50 e 60, respectivamente, nem o contrário, a de entender o "estrangeiro" como sinônimo de renovação, o que nos lembra o impacto negativo de uma agressiva política pelo "outro" em Campinas, que resultou, a médio prazo, no enfraquecimento do próprio salão e do museu que o recebia. Além disso, é necessário lembrar que a "identidade", enquanto categoria sócio-histórica, não é algo que sempre esteve latente, à espera de ser encontrada e representada. Muito menos algo que sempre estará à disposição na forma que lhe foi dada em um momento histórico específico por sujeitos particulares. "Existe sempre algo imaginário ou fantasiado em sua unidade. Ela permanece sempre incompleta, em 'processo', sempre 'em formação', fragmentada." ${ }^{65} \mathrm{E}$ os discursos engendrados pelos salões mencionados não são imunes à tensão entre a tentativa de fixação e a movência identitária.

De outra forma, Brasília parece corporificar a regra. O conservadorismo local encontrou grande dificuldade em absorver novas temáticas e propostas oriundas das experimentações das artes visuais, sem, contudo, ater-se às questões identitárias, o que, sobremaneira, já chama atenção para as idiossincrasias da capital recém-criada. De todo modo, cabe outro trabalho para 
tentar compreender o real impacto da política repressiva sobre os discursos identitários e sobre o manejo das preferências artísticas dentro das instituições. Por certo, os salões de arte mostram-se privilegiadas arenas para a compreensão de questões próprias da história da arte assim como de outras áreas da história.

\section{NOTAS}

' CANONGIA, Ligia. O legado dos anos 60 e 70. Rio de Janeiro: Jorge Zahar Editor, 2005.

${ }^{2}$ Foram escolhidos, assim, museus localizados em centros regionais de cultura que tivessem o papel simultâneo de centros ex-cêntricos, expressão da crítica Aracy Amaral (AMARAL, A. Cêntricos e ex-cêntricos: que centro? onde está o centro? In: __. Textos do Trópico de Capricórnio. v. 2: Circuitos de arte na América Latina e no Brasil. São Paulo: Ed. 34, 2006. p.9l). Tal critério teve como objetivo selecionar instituições que estavam fora do circuito internacional de arte; instituições que não organizam ou acolhem megaexposições, simpósios e bienais de alcance internacional (BENHAMOU, Françoise. Os mercados de arte e o patrimônio. In: A economia da cultura. Tradução de Geraldo Gerson de Souza. Cotia-SP: Ateliê Editorial, 2007. p. 75- 108).

3 PECCININI, Daisy. Figurações: Brasil anos 60. São Paulo: Itaú Cultural e Edusp, 1999.

4 "[Os] salões surgiram quase ao mesmo tempo em que os museus de arte, instituições teoricamente neutras e acessíveis a todos, marcados pela sacralização de seu espaço físico, continente de um 'patrimônio comum a todos', que são as obras de arte. A análise de uma instituição é complementar à outra."; CATTANI, Icleia. Os salões de arte são espaços contraditórios. In: FERREIRA, Glória (org.). Crítica de Arte no Brasil: temáticas contemporâneas. Rio de Janeiro: Funarte, 2006. p. 263.

${ }^{5}$ LUZ, Angela A. Uma breve história dos Salões de Arte: da Europa ao Brasil. Rio de Janeiro: Caligrama, 2005; Ainda sobre a relação entre a Academia Imperial de Bellas Artes e os salões, Cybele Fernandes demonstra como os últimos foram manejados como elemento político primordial para autorizar os valores artísticos vigentes, o que não excluía as tensões entre seus membros e toda uma classe política extramuros; FERNANDES, Cybele Vidal Neto Os caminhos da arte: o ensino artístico na academia Imperial das Belas Artes - 1850- | 890. Tese (Doutorado no Programa de Pós-Graduação em História). Universidade Federal do Rio de Janeiro, 2001 .

${ }^{6}$ Jornal Gazeta do Povo, A Fundação da Sociedade dos Artistas do Paraná. Curitiba, II jan. 1931 .

${ }^{7}$ Os premiados foram: Guido Viaro (1952); Nilo Previdi (1953); Arthur Nísio ( 1954); Estanislau Traple ( 1955); JUSTINO, M. J. 50 anos do Salão Paranaense de Belas Artes. Curitiba: SEC/MACPR, 1995. p. 257-259.

${ }^{8}$ BURLAMAQUI, Maria Cristina. O Salão de 3 I : uma reavaliação. In: VIEIRA, L.G. Salão de 193 I: marco da revelação da arte moderna em nível nacional. Rio de Janeiro: Inap - Funarte, 1984

${ }^{9}$ LUZ, Op. cit., p. I 18.

10 Nome fundamental desse movimento foi Alfredo Romário Martins, com sua História do Paraná, obra publicada em 1899, e a fundação do Instituto Histórico, Geográfico e Etnográfico Paranaense em 1900; sobre a importância de Martins para o movimento paranista: SILVA, W. P. Reflexões sobre a influência de Romário Martins na historiografia paranaense. Revista Guairacá, Guarapuava-PR, v. 17, p. 99-109, 200 I. Sobre o paranismo: PEREIRA, L. F. Paranismo - o Paraná inventado: cultura e imaginário no Paraná da I República. Curitiba: Aos quatro ventos, 1997; para compreender a relação de Martins com as questões de memória e identidade do Paraná: CARNEIRO, Cíntia M. S. B. O. Museu Paranaense e Romário Martins: a busca de uma identidade para o Paraná (19021928). Dissertação (Mestrado no Programa de Pós-Graduação em História). Universidade Federal do Paraná, 200 I. 
" É sintomático que em 1946 surgisse a Folha da Juventude e, no ano seguinte, as revistas Cicuta e Revista Sul, em Florianópolis, que, em seus modos e consequências, também combateram um certo provincianismo catarinense. Contudo, a geração Joaquim não constituiu um museu, como foi o caso do movimento catarinense que se empenhou na criação do Museu de Arte Moderna de Florianópolis, hoje o MASC; SABINO, L. L. As propostas do 'Grupo Sul'. Revista Travessia, v. I, Florianópolis: UFSC, 1980.

12 JUSTINO, Op. cit. p. 3. A autora lembra-nos de que Viaro muda de ideia dez anos depois, quando publica "O salão paranaense é dos paranaenses" no jornal O Estado do Paraná (Curitiba, 15 de novembro de 1958); idem, ibidem, p. 4.

${ }^{13}$ Organizado por Constantino Viaro, Adalice Araújo, Luiz Carlos de Andrade Lima, Alcides Teixeira, Jair Mendes e Ivany Moreira; FERREIRA, Ennio Marques. 40 anos de amistoso envolvimento com a arte. Curitiba: Fundação Cultural, 2006. p. 293.

${ }^{14}$ O I Colóquio da Associação dos Museus de Arte do Brasil (AMAB), realizado em São Paulo, em 1966, teve forte papel na criação de inúmeros museus pelo país, entre eles o MACPR. Foi nesse evento que Ennio Marques Ferreira conseguiu um documento destinado ao Secretário de Educação e Cultura do Paraná, assinado por outros diretores e críticos, exigindo a criaçãa e administração do Museu de Arte do Estado do Paraná; "O SALÃO NACIONAL DE ARTE MODERNA E A DESCENTRALIZAÇÃO DAS ATIVIDADES CULTURAIS DO MEC" (Proposição apresentada pelo DC/SEC/PR por ocasião do I Colóquio de Dirigentes de Museus, MAC/USP, São Paulo, 27-28 de setembro de 1966). v. $1^{\circ} 2^{\circ} 3^{\circ}$ Colóquios de Museus de Arte do Brasil. Documentos encadernados do Setor de Pesquisa e Documentação do MAC/PR.

${ }^{15}$ BINI, Fernando. Fernando Velloso: o seguro exercício da forma e da cor. Curitiba: F. Bini, 2003. p. 10.

16 VIRMOND, E.R. "O movimento abstrato". In: MUSEU DE ARTE CONTEMPORÂNEA DO PARANÁ. Tradição/Contradição. Catálogo de exposição. Curitiba: SECP, 1986. p. I 6.

17 Texto de apresentação da mostra "Obras Recentes" no Hotel Nacional, em Braślia, de Eduardo Rocha Virmond. In: BINI, Op. cit., p. 16.

${ }^{18}$ FREITAS, Artur. "A consolidação do moderno na história da arte no Paraná". Revista de História Regional, Ponta Grossa-PR, v. 8, n. 2, p II 3 e; COUTO, Maria de Fátima Morethy. Por uma vanguarda nacional: a crítica brasileira em busca de uma identidade artística ( 1940- 1960). Campinas, SP: Editora da Unicamp, 2004. p. 75-99.

${ }^{19}$ Anna Bella Geiger, Dora Basílio, Helerna Wong, Dorothy Bastos, Marília Rodrigues, Yo Yoshitome, Tikashi Fukusima, João Brzezinski, José Assumpção de Souza, Walter Marques, Raul Porto, Antonio Maia, Hisao Ohara, Lothar Charoux, Érico da Silva, entre outros; JUSTINO, Op. cit.

${ }^{20}$ A Pinacoteca Municipal era uma reivindicação dos artistas "acadêmicos" da cidade, que desejavam ver as obras adquiridas pela Prefeitura Municipal nos Salões de Belas Artes protegidas numa instituição que respaldasse a produção local. Embora o nome permanecesse, é preciso salientar que, já em 1965, os artistas que trabalharam pela constituição de um museu não estavam mais filiados ao pensamento acadêmico.

${ }^{21}$ Depoimento do artista Francisco Biojone ao autor, em 17 de junho de 2003, em seu ateliê em Campinas-SP.

${ }^{22}$ Sobre as histórias de vínculo entre o MAM e o MAC/USP: AMARAL, Aracy. "Do MAM ao MAC: a história de uma coleção". In: (org.). Museu de Arte Contemporânea da Universidade de São Paulo: perfil de um acervo. São Paulo: Techint: MAC/USP, 1988.

${ }^{23}$ Depoimento de Thomaz Perina ao autor, 28 de agosto de 2007. Da primeira investida de 1957 participaram os artistas: Aristides Ferraz, Enéas Dedécca, Geraldo Décourt, Geraldo Jurgensen, Geraldo de Souza, Maria Helena Mota Paes, Mário Carneiro, Raul Porto e Thomaz Perina e os 
italianos Franco Sachi, Edoardo Belgrado, Ermis de Bernardi e Lélio Coluccini.

${ }^{24}$ Jornal Correio Popular. Artes Plásticas. Exposição conjunta de pintores modernistas campineiros, texto de José de Castro Mendes. Campinas, 05 set. 1957.

${ }^{25}$ Participaram da segunda edição de junho de 1958: Enéas Dedécca, Geraldo Décourt, Geraldo Jurgensen, Geraldo de Souza, Maria Helena Mota Paes, Mário Carneiro, Raul Porto e Thomaz Perina e os italianos Franco Sachi, Edoardo Belgrado, Ermis de Bernardi; FONSECA, Days Peixoto. Grupo Vanguarda (1958-1966). Registro histórico através de resenha jornalística e catálogos. Campinas: Museu da Imagem e do Som de Campinas, 1981.

${ }^{26}$ FONSECA, Days Peixoto; SILVA, José Armando Pereira da. Thomaz Perina. Pintura e Poética. Campinas: s.n., 2005. p. 44.

27 Zago demonstra que a finalidade dos SACCs era a criação e a consolidação de um museu, e não o contrário; ZAGO, Renata. Os Salôes de Arte Contemporânea de Campinas. Dissertação de Mestrado (Programa de Pós-Graduação do Instituto de Artes) Instituto de Artes. Universidade Estadual de Campinas, 2007.

${ }^{28}$ Jornal Correio Popular, SAC: Arte de Vanguarda na Avenida da Saudade. Campinas, 29 de agosto de 1965, p. 19.

${ }^{29}$ Depoimento de Fancisco Biojone ao autor em 17 de junho de 2003, em seu ateliê em Campinas$\mathrm{SP}$.

${ }^{30}$ Nos três primeiros salões, os prêmios estavam divididos em Medalhas de Ouro, Prata e Bronze; em especial o II e o III. Tais medalhas ainda eram subdivididas em Grande e Pequena; OLIVEIRA, E.D.G. A visibilidade dos acervos de arte contemporânea no Brasil. Porto Alegre: Zouk, 201 0, p.243.

${ }^{31}$ Museu de Arte Contemporânea de Campinas. VI Salão de Arte Contemporânea de Campinas. Campinas: MACC, 1969. Catálogo de exposição apud ZAGO, Op. cit., p. 18.

${ }^{32}$ Depoimento do artista Raul Porto; CAMPOS, Crispim Antônio. Um olhar sobre o Grupo Vanguarda: uma trajetória de luta, paixão e trabalho. Dissertação (Mestrado). Faculdade de Educação. Campinas: Universidade Estadual de Campinas, 1996, anexos.

${ }^{33}$ Nesse salão inusitado, doze renomados artistas foram convidados a apresentar 40 slides de trabalhos realizados: "Enfim um salão sem quadros. Ou quase isso. Ao se realizar pela décima vez, na semana passada, o Salão de Arte Contemporânea de Campinas (SP) apresentava essa radical inovação. Convidados pelo museu local (pertencente à Prefeitura, que patrocina o certame), três críticos de arte tiveram total liberdade para propor o projeto de salão que lhes parecesse o mais indicado para o momento atual. E, reunidos em meados de julho passado, Aracy Amaral, Aline Figueirado e Frederico Morais acabaram optando pela palavra. Isto é: em vez do costumeiro sistema de artistas enviando quadros, submetendo-se a júris, disputando prêmios e assim por diante, os três críticos resolveram transformar em um grande debate ilustrado." Revista Veja, "Vez da Palavra", 19 de novembro de 1975.

${ }^{34}$ ÁVILA, Cristina. Aníbal Mattos e seu tempo. Belo Horizonte: Museu de Arte da Pampulham, 1991, p. I5. Dois fatos não podem ser esquecidos quanto à história do modernismo em Belo Horizonte. Ainda que de impacto mais simbólico do que prático, a exposição Zina Aita, em 1920, e a conferência de Flávio de Carvalho, em 1930, foram eventos que indicavam o desejo de uma parcela da classe artística da cidade em sintonizar-se como o movimento modernista dos grandes centros.

${ }^{35}$ VIEIRA, Ivone. A escola Guignard na cultura modernista de Minas (1944- 1962). Pedro Leopoldo: Cia de Empreendimentos Sabará, 1988.

${ }^{36}$ MOURA, Antonio da Paiva. Memória Histórica da Escola Guignard. Belo Horizonte: Editora Usina de Livros, 1993, p.8- I0. Para Moura, apenas com a fundação da Escola de Belas Artes Belo- 
Horizonte, em 1951, que a Escola Guignard (nome atribuído apenas em 1962) fixa-se, não sem conhecer dificuldades ainda no final daquela década; idem, p. 14.

37 ANDRADE, Rodrigo Vivas. Os Salões Municipais de Belas Artes e a emergência da Arte Contemporânea em Belo Horizonte: 1960- 1969. Tese de Doutorado. Instituto de Filosofia e Ciências Humanas. Universidade Estadual de Campinas, 2008.

38 RIBEIRO, Marília Andrés. Neovanguardas: Belo Horizonte - anos 60. Belo Horizonte: Editora C/Arte, 1997.

39 Os prêmios na categoria de pintura foram para Aldo Malagoli ( ${ }^{\circ}$ lugar), Tikashi Fukushima (2 lugar) e Anatol Wladislaw ( $3^{\circ}$ lugar). A única obra disponível no acervo do MAP é de Malagoli, Abstração com ponto vermelho; obra que denota que a presença de Sanson Flexor no júri parece ter influenciado a direção das premiações.

40 Texto de Wilson Frande publicado no Estado de Minas em 04 de dezembro de 1963 apud ANDRADE, Op. cit.

4I Idem.

42 Idem.

43 Texto de Ivan Ângelo, publicado no Diário de Minas, em 27 de novembro de 1965, apud ANDRADE, Op. cit. Os jurados dessa edição foram: Marc Berkowitz, Maristela Tristão, Pierre Santos, Vera Pacheco Jordão e Walter Zanini.

${ }^{44}$ REIS, Paulo. Arte de vanguarda no Brasil. Rio de Janeiro: Jorge Zahar Editor, 2006.

${ }^{45}$ Frederico Morais, Jacques de Prado Brandão, Jayme Maurício, Morgan Motta e Walter Zanini.

${ }^{46}$ Texto de Wilson Frade publicado no jornal Estado de Minas em 24 de novembro de 1967.

${ }^{47}$ RIBEIRO, Op. cit., p. 191.

${ }^{48}$ ANDRADE, Op. cit.

${ }^{49}$ RIBEIRO, Op. cit., p. 187.

50 Idem, ibidem, p. 197.

51 Idem, p. 199.

$52 \bigcirc$ termo é emprestado da Agnes Heller e voltado para os trânsitos culturais globais; HELLER, Agnes. "Memoria Cultural, Identidad y Sociedad Civil". Revista Internacional de Ciencias Sociales y Humanas n. I, 2003, p. 5-18.

53 FRASER, V. "Brasília: Uma Capital Nacional sem um Museu Nacional". In: Fórum Permanente de Museus de Arte: entre o público e o privado; acesso em 16 de fevereiro de 2007; disponível em: http://forumpermanente.incubadora.fapesp.br/portal/.painel/artigos/val_fraser/; COSTA, Horacio. "Carta de Brasil - Brasília: una ciudad sin museos y con políticos", Cuā̄ernos Hispanoamericanos, n. ${ }^{\circ}$ 587, Madri, maio de 1999. p. I51-169.

${ }^{54}$ Vale lembrar que os artistas residentes em Brasília obtiveram prêmios diferentes daqueles conferidos aos artistas considerados profissionais. No I SMAB, Paulo lolovitch, na pintura, e Éster Joffily, na gravura. A ausência de uma documentação sistematiza permanece um grande empecilho para a compreensão dos três primeiros SAMBs; Jornal Correio Brasiliense, "Arte Moderna na Cidade Moderna". Brasília, 23 de junho de 1964; Jornal Correio Brasiliense, "O rei está nu!", texto de Regina Laet. Brasília, 10 de novembro de 1966; ANDRADE, Marco A.P.. "Da abstração informal à perceptiva de Brasília: os salões de Arte Moderna do Distrito Federal nos anos 60" In: MARTINS A.; COSTA, L.; MONTEIRO, R. Cultura visual e desafios da pesquisa em artes. v. 2. Goiânia: ANPAP, 2005. p. 224-234. 
${ }^{55}$ Essa crise já estava anunciada com a divisão dos salões nacionais entre Belas Artes e Arte Moderna em 195I; LUZ, Op. cit., p. 126.

${ }^{56}$ LOPES, Fernanda. A experiência Rex. "Éramos o time do Rei". São Paulo: Alameda, 2009. p. 224.

${ }^{57}$ Revista e do Sesc-SP, n. 78, nov. 2003. Disponível em: http://www.sescsp.org.br/ sesc/revistas/ revistas_link_home.cfm?Edicao_Id=170\&breadcrumb=2\&tipo=3 Acesso em: I 4 jun. 2007

58 PEDROSA, M. "Do porco empalhado ou os critérios da crítica". In: FERREIRA, Glória (org.). Crítica de Arte no Brasil: temáticas contemporâneas. Rio de Janeiro: Funarte, 2006. p. 210.

${ }^{59}$ FIGUEIREDO, A. Artes plásticas no Centro-Oeste. Cuiabá: UFMT, Museu de Arte e de Cultura Popular, 1979. p. 19.

${ }^{60}$ MORAIS, Frederico. Artes plásticas - a crise da hora atual. Rio de Janeiro: Paz e Terra, 1975. p. I0 1.

${ }^{61}$ LAET, Regina. "O rei está nú!". Jornal Correio Brasiliense. Braślia, I0 nov. 1966.

62 FIGUEIREDO, Op. cit., p. 19.

${ }^{63}$ Sobre a importância dos salões para outras instituições: FARIAS, A.; ANJOS, M. dos. A geração da virada. 10+1: os anos recentes da arte brasileira. Catálogo de exposição. São Paulo: Instituto Tomie Ohtake, 2006. p. 47-59; agradeço à Profa. Dária Jaremtchuk pela indicação dessa obra.

${ }^{64}$ Especialmente sobre o período militar, Ronaldo Brito comentou: "O problema como sempre é que com toda sua irrealidade o salão age sobre o real. Numa certa instância é um dispositivo de relacionamento do Estado com a produção de arte, em outra se insere como evento cultural que pretende realizar uma leitura crítica do processo local das linguagens, daí a existência de júris e premiações. Esses são os dois eixos de análise possíveis. Quanto ao primeiro digamos apenas que o salão serve para indicar o desinteresse do Estado por uma atividade tão vaga e remota, o que já seria possível notar pela ausência de censura na área. De modo que tudo fica a cargo da burocracia e sua conhecida capacidade de mumificar o presente. É claro que o salão nesse sentido enrijece ainda mais o preconceito vigente no meio cultural brasileiro contra a arte: sabe-se que amplos setores da esquerda concordam em reputá-la mundana, elitista, desligada do real e dedicam a ela o melhor do seu desprezo moral, sem procurar contato com a produção contemporânea e as questões que trabalha."; BRITO, Ronaldo. "Casa da titia". In: LIMA, Sueli de (org.). Experiência crítica - textos selecionados: Ronaldo Brito. São Paulo: Cosac Naify, 2005. p. 72; texto de janeiro de 1977 que comenta o VII Salão Paulista de Arte Contemporânea (I 4/I2//6 a 30/0 I/77).

${ }^{65}$ FLORES, Maria Bernardete Ramos. Tecnologia e estética do racismo: ciência e arte na política da beleza. Chapecó, SC: Argos, 2007. p. 95.

\section{Artigo recebido em fevereiro de 20 I 0 . Aceito em julho de 201 I.}

